\title{
Biological approach to aflatoxin control in stored poultry feed
}

\author{
Syeda Mona Hassan ${ }^{1}$, Bushra Sultana², Munawar Iqbal ${ }^{3}$, Saima $\mathrm{Naz}^{4}$ \\ ${ }^{1}$ Lahore Garrison University, Department of Chemistry, Lahore, Pakistan \\ ${ }^{2}$ University of Agriculture Faisalabad, Department of Chemistry, Faisalabad, Pakistan \\ ${ }^{3}$ University of Lahore, Department of Chemistry, Lahore, Pakistan \\ ${ }^{4}$ Bahauddin Zakariya University, Institute of Chemical Sciences, Multan, Pakistan
}

Received January 25, 2016

Accepted February 17, 2017

\begin{abstract}
The anti-aflatoxigenic potentials of the leaves of Psidium guajava, Ficus benghalensis, Gardenia radicans, Punica granatum and Ziziphus jujuba Mill. were investigated. Poultry feed inoculated with Aspergillus flavus was treated with plant leaves powder and stored for the period of six months at $28{ }^{\circ} \mathrm{C}$ and $16 \%$ moisture level. At the end of each month, aflatoxin (AFT) concentrations were determined by high performance liquid chromatography. The proximate and mineral analysis was performed at the end of the storage period. Plant leaves control the AFTs (AFB1 and AFB2) efficiently without compromising the feed quality. Punica granatum leaves $(5 \%)$ completely inhibited the AFTs in the stored feed over the period of six months. Ziziphus jujube Mill., P. guajava, F. benghalensis, and G. radicans also showed promising antiaflatoxigenic activities. Results revealed that the AFT production by A. flavus in a stored poultry feed can be inhibited using the plant leaves under investigation.
\end{abstract}

Anti-aflatoxigenic activity, medicinal plant, storage conditions, nutritional quality, high performance liquid chromatography

Poultry farming has gained importance throughout the world and has become a dynamic industry in South Asian countries since protein demand is increasing day by day (Mahesar et al. 2010). At present, more than 140 poultry feed mills are operating with an annual capacity of $\sim 4$ million tonnes of feed to meet the feed demand of poultry farms in Pakistan (MLD 2009). Poultry feed comprises peanuts, cotton seeds, cereal grains and proteins (soya been, corn gluten, copra and sunflower) (Ahmad et al. 2012; Anjum et al. 2012). Since the feed is used throughout the year, it is stored for months. Factors such as prolonged storage, variation in temperatures, feed composition and storage conditions play an important role in the fungal growth which contaminates the feed (Stack and Carlson 2003; Iqbal et al. 2015b). Aflatoxins (AFTs) not only decrease the quality of food and feed, but also adversely affect the health of organisms. Moreover, AFTs then also appear in meat and milk, affecting human beings (Anjum et al. 2012).

Aspergillus flavus is one of the dominant microbes responsible for contamination of feed and other agricultural commodities. Aflatoxins are reported to be genotoxic, carcinogenic, teratogenic, and hepatotoxic in nature (Stack and Carlson 2003; Iqbal et al. 2015b). The tropical regions are facing difficulties controlling AFT contamination. In spite of precautionary measures, absolute safety has never been achieved. Although certain fungicides have been known to inhibit the A. flavus growth during storage, consumer apprehension about possible risks linked with fungicides resulted in extensive search for more effective and safer control strategies (Chow 1980). Chemical detoxification involves the use of chemical agents (Shi et al. 2006), whereas physical methods comprise radiation and microwave heating (Inan et al. 2007) On the other hand, biological approaches are more effective and safer for AFTs and in this regard, plants are the rich sources of

Address for correspondence:

Syeda Mona Hassan

Department of Chemistry

Lahore Garrison University

Lahore, Pakistan 
phytochemicals which have promising fungicidal activities (Saxena et al. 2013). The use of medicinal plants to control AFTs is of great importance since these are safer in comparison to chemical or physical treatments (Volcani Center 2004; Shi et al. 2006; Inan et al. 2007; Asif 2015a,b,c,d,e,f; Adaramola et al. 2016; Hamid et al. 2016; Adaramola and Onigbinde 2017). Moreover, in view of the current scenario of environmental pollution (Iqbal and Bhatti 2015; Iqbal et al. 2015a; Iqbal and Nisar 2015; Qureshi et al. 2015; Sayed 2015; Iqbal 2016; Mushtaq et al. 2016; Nadeem et al. 2016; Peter and Chinedu 2016; Tahir et al. 2016a,b; Ukpaka 2016a,b,c; Iqbal et al. 2017; Ngobiri and Okorosaye-Orubite 2017; Shoukat et al. 2017), there is a need to adopt safe and eco-friendly methods.

Medicinal plants (Psidium guajava, Ficus benghalensis, Gardenia radicans, Punica granatum and Ziziphus jujuba Mill.) were investigated for inhibition of AFTs in stored broiler feed. The aim of this research was to evaluate their potential to inhibit AFTs produced by $A$. flavus during storage. The treatment efficiency was evaluated on the basis of AFT inhibition and nutritional value of the stored feed over the period of six months of storage.

\section{Materials and Methods}

\section{Chemicals and reagents}

The culture media and standard antibiotic discs were purchased from Oxoid Ltd., (Hampshire, UK). Aflatoxin standards were purchased from Supelco (Bellefonte, PA, USA). All other reagents and chemicals, i.e., methanol, acetonitrile, and $n$-hexane used were of analytical grade (Merck, Darmstadt, Germany). Trifluoroacetic acid (TFA) of Riedel-de Haen was used as the derivatizing agent to enhance fluorescence. The immunoaffinity column was purchased from AflaTest ${ }^{\circledR}$ WB VICAM, USA.

Plant collection, extraction and extract preparation

Psidium guajava, Ficus benghalensis, Gardenia radicans, Punica granatum and Ziziphus jujuba Mill. plant leaves were collected from the Botanical Garden of the University of Agriculture, Faisalabad, Pakistan. The selected plant leaves were washed, dried under ambient conditions followed by oven drying at $70{ }^{\circ} \mathrm{C}$ to constant weight, and then grinded to fine powder.

\section{Antifungal activity}

Antifungal extracts were prepared from the leaves by dissolving $10 \mathrm{~g}$ powder in $100 \mathrm{ml}$ methanol $(80 \%)$ and shaken (Gallenkamp, UK) for $24 \mathrm{~h}$ at room temperature. The mixture was filtered to separate the extract from residues. The extracts were concentrated under reduced pressure at $45^{\circ} \mathrm{C}$ (EYELA, N-N Series, Rikakikai Co. Ltd., Tokyo, Japan) and stored in a refrigerator at $4{ }^{\circ} \mathrm{C}$.

For inoculum preparation, pure fungal strains were obtained from the Department of Clinical Medicine and Surgery, University of Agriculture, Faisalabad, Pakistan. The fungal strains were cultured on the potato dextrose agar (Oxoid, UK) slant and incubated at $28^{\circ} \mathrm{C}$ until sporulation ( 7 days). The spores were harvested in sterilized distilled water containing $0.1 \%$ Tween 80 and were counted in the Nebauer chamber with microscopy. The suspension containing $1 \times 10^{7}$ spores $/ \mathrm{ml}$ was preserved at $4{ }^{\circ} \mathrm{C}$.

For antifungal activity, $20 \mathrm{ml}$ PDA solution containing $1 \times 10^{7}$ spores $/ \mathrm{ml}$ was spread on sterile Petri dishes. Sterilized discs $(6 \mathrm{~mm})$ were impregnated with extract $(50 \mu \mathrm{l})$ and incubated at $28^{\circ} \mathrm{C}$ for $48 \mathrm{~h}$ (Wayne 2002). Fluconazole $(30 \mu \mathrm{g} / \mathrm{disc})$ (Oxoid, UK) was used as positive control. The zones of inhibition diameter were measured $(\mathrm{mm})$ by a zone reader.

For MIC estimation, $100 \mu \mathrm{l}$ of extract $(10 \mathrm{mg} / \mathrm{ml})$ was transferred to 96 well plates and $50 \mu \mathrm{l}$ of Sabouraud dextrose broth (SDB) was added to all wells. Series of dilutions were prepared in a descending concentration order. Finally, $10 \mu \mathrm{l}$ of fungal suspension $\left(1 \times 10^{7}\right.$ spores $\left./ \mathrm{ml}\right)$ were added to each well. The plates were incubated at $28{ }^{\circ} \mathrm{C}$ for $48 \mathrm{~h}$. The absorbance was measured at $620 \mathrm{~nm}$ by ELISA reader and MIC was estimated in $\mu \mathrm{g} / \mathrm{ml}$ (Sharma and Kumar 2008).

\section{Feed sample treatment}

Fresh and toxin free poultry feed samples $(4 \mathrm{~kg})$ were obtained from Punjab Feed Corporation, Lahore road, Sheikhupura, Pakistan. The feed sample was dried in an oven at $60{ }^{\circ} \mathrm{C}$ and divided into 16 parts $(200 \mathrm{~g})$. Each lot was autoclaved, then, moistened $(16 \%)$ with sterilized distilled water. The feed samples were inoculated by $4 \mathrm{ml}$ of $A$. flavus suspension $\left(1 \times 10^{7}\right.$ spores $\left./ \mathrm{ml}\right)$ under laminar air flow (Dalton, Japan).

Plant leaves powder at three different concentrations $(5,10$ and $15 \% \mathrm{w} / \mathrm{w})$ were added separately in $200 \mathrm{~g}$ of inoculated feed. Non-treated feed samples were considered as control. The treated and control samples were 
stored at $16 \%$ moisture and $28{ }^{\circ} \mathrm{C}$ for six months. At the end of each month, feed samples were drawn and AFTs were (AFB1 and AFB2) determined by HPLC.

\section{Aflatoxin extraction and analysis}

Two types of AFTs (aflatoxin B1 and aflatoxin B2) were measured as described by Mushtaq et al. (2012). Briefly, the treated feed sample $(5 \mathrm{~g})$ was taken in a conical flask and $20 \mathrm{ml}$ of acetonitrile-water $(84: 16 \mathrm{v} / \mathrm{v})$ was added and shaken for $90 \mathrm{~min}$ in an orbital shaker at ambient conditions. The content was filtered and the filtrate was concentrated under reduced pressure to 4-5 ml. Concentrated sample $(2 \mathrm{ml})$ was diluted with $20 \mathrm{ml}$ of deionized water and passed through Vicam (AflaTest WB Columns, Vicam, USA) at the flow rate of $2 \mathrm{ml} / \mathrm{min}$ using a suction pump. The column was washed with $20 \mathrm{ml}$ of deionized water, and then dried by air streaming for 1-2 min. The AFTs from the column were eluted using methanol ( $1 \mathrm{ml}$, twice). The samples were dried under $\mathrm{N}_{2}$ blanketing. For derivatization, the dried sample was vortexed with $200 \mu \mathrm{l}$ of $n$-hexane for $30 \mathrm{~s}$; then $50 \mu \mathrm{l}$ of trifluoroacetic acid was added and again vortexed for $30 \mathrm{~s}$. Finally, $1.95 \mu \mathrm{l}$ water : acetonitrile $(9: 1 \mathrm{v} / \mathrm{v})$ was added and vortexed for $20 \mathrm{~s}$, and the resultant mixture $(20 \mu \mathrm{l})$ was subjected to HPLC analysis. The LC-system (Shimadzu LC LC-10A Series, Shimadzu, Japan) was used for the estimation of AFTs. Isocratic mobile phase consisting of acetonitrile, methanol and water $(22.5: 22.5: 55)$ was used at a flow rate of $1 \mathrm{ml} / \mathrm{min}$. Calibration curve was drawn using a series of FATs concentrations $(0.05,0.1,0.5,1.0,5.0,10 \mu \mathrm{g} / \mathrm{l})$ in acetonitrile. The AFTs inhibition was calculated using the relation shown in the following equation, where $X$ is the concentration of AFTs in treated samples and $Y$ is the concentration of AFTs in control (un-treated sample):

Inhibition $(\%)=\left[\frac{X-Y}{Y}\right] \times 100$

Proximate and mineral analysis

The proximate composition (ash, protein, fat, and fiber) and mineral profile of treated and un-treated feed samples were measured at the end of the storage period. For the proximate composition, AOAC standard methods were adopted (AOAC 1990). For mineral analysis, calcium (Ca) and iron (Fe) contents were analyzed by AAS (Hitachi Polarized Zeeman AAS, Z-8200, Japan) (AOAC 1990). Potassium (K) was determined using flame photometer (PFP7, Jenway, Japan), whereas phosphorus (P) was determined by UV-Vis spectrophotometer (Lambda-25, Perkin Elmer, USA) (Khalil and Mannan 1990).

Statistical analysis

All experiments were performed in triplicate and the data thus obtained were reported as means $\pm \mathrm{SD}$. Analysis of variance (ANOVA) was performed at $P<0.05$ confidence level using Minitab statistical software (Minitab Inc. Pennsylvania, U.S.A).

\section{Results}

\section{Antifungal activity of medicinal plant leaves}

The antifungal activities of medicinal plant leaves are given in Table 1. All plants showed a considerable antifungal activity against $A$. flavus and variation among plants was significantly $(P<0.05)$. Punica granatum leaf extract showed highest activity $(19 \mathrm{~mm})$ followed by Ziziphus jujuba Mill., Ficus benghalensis, Psidium guajava, and Gardenia radicans. The MIC values against $A$. flavus are given in Table 1 . The MIC values indicate

Table 1. Antifungal activity and minimum inhibitory concentration (MIC) of medicinal plant leaf extracts against Aspergillus flavus.

\begin{tabular}{lcc}
\hline Medicinal plant & Zone diameter $(\mathrm{mm})$ & MIC $(\mu \mathrm{g} / \mathrm{ml})$ \\
\hline Psidium guajava & $11.0 \pm 1.52^{\mathrm{d}^{*}}$ & $121.11 \pm 0.76^{\mathrm{b}}$ \\
Ficus benghalensis & $15.0 \pm 2.51^{\mathrm{c}}$ & $103.20 \pm 1.09^{\mathrm{c}}$ \\
Gardenia radicans & $10.0 \pm 2.51^{\mathrm{d}}$ & $132.50 \pm 0.54^{\mathrm{a}}$ \\
Punica granatum & $19.0 \pm 1.00^{\mathrm{b}}$ & $73.60 \pm 0.73^{\mathrm{d}}$ \\
Ziziphus jujuba Mill. $^{\mathrm{b}}$ & $16.0 \pm 1.52^{\mathrm{c}}$ & $77.50 \pm 1.07^{\mathrm{cd}}$ \\
Flucanozole (control) & $26.0 \pm 1.00^{\mathrm{a}}$ & $41.20 \pm 1.00^{\mathrm{e}}$ \\
\hline
\end{tabular}

$\mathrm{MIC}=$ Minimum inhibitory concentration, *Values are mean \pm $\mathrm{SD}$ of triplicate runs. Superscripts within column are showing significant difference $(P<0.05)$ among plants that the medicinal plant has potent antifungal activities, inhibiting the growth of A. flavus at relatively small concentrations (Mahoney and Molyneux 2004).

\section{Aflatoxin inhibition}

Feed samples treated with different concentrations of medicinal plant leaf powder were stored for a period of six months and the AFT (AFB1 and AFB2) concentrations were determined at the end of each month. The obtained results are shown 

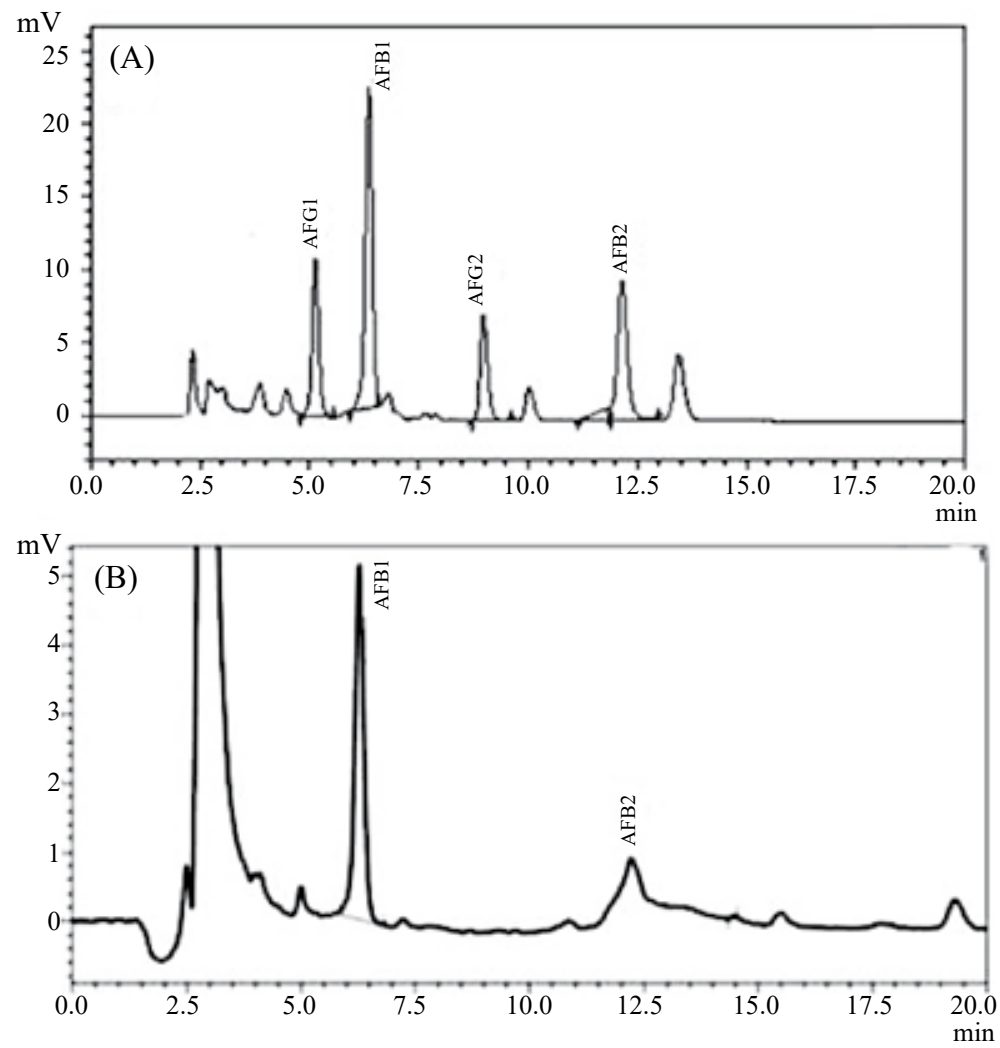

Fig. 1. HPLC chromatograms (A) standard aflatoxins, (B) aflatoxins (AFB1 and AFB2) in A. flavus contaminated feed samples

in Table 2 and typical HPLC chromatograms are shown in Fig. 1. All the treatments inhibited the AFTs in a concentration-dependent manner. Punica granatum at a 5\% concentration inhibited the AFTs up to $100 \%$ throughout the storage period. The effect of $Z$. jujuba Mill. on AFTs inhibition was also promising and the values of Psidium guajava treated feed samples were significantly lower than the control. Ficus benghalensis was also found to be efficient for AFT control; the values of Gardenia radicans leaf treated feed samples were significantly lower than control. The detected AFTs in stored feed samples without leaf powder treatments were considerably higher than the recommended limits for feed.

Proximate composition and mineral contents of treated feed

The results of proximate analysis of the treated feed inoculated with A. flavus are given in Table 3. The proximate composition was recorded to be stable in the feed at the end of the six months of storage. Interestingly, it was observed that at higher concentration, the decrease in proximate composition was low, i.e. that the proximate composition changed in concentration dependent manner. Overall, it was observed that feed samples treated with plant leaf powder showed stability in proximate composition versus control.

Results revealed that feed treated with plant leaves did not change the mineral contents over the entire storage period of storage. Similarly to proximate composition, minerals also showed stability (Table 4). 


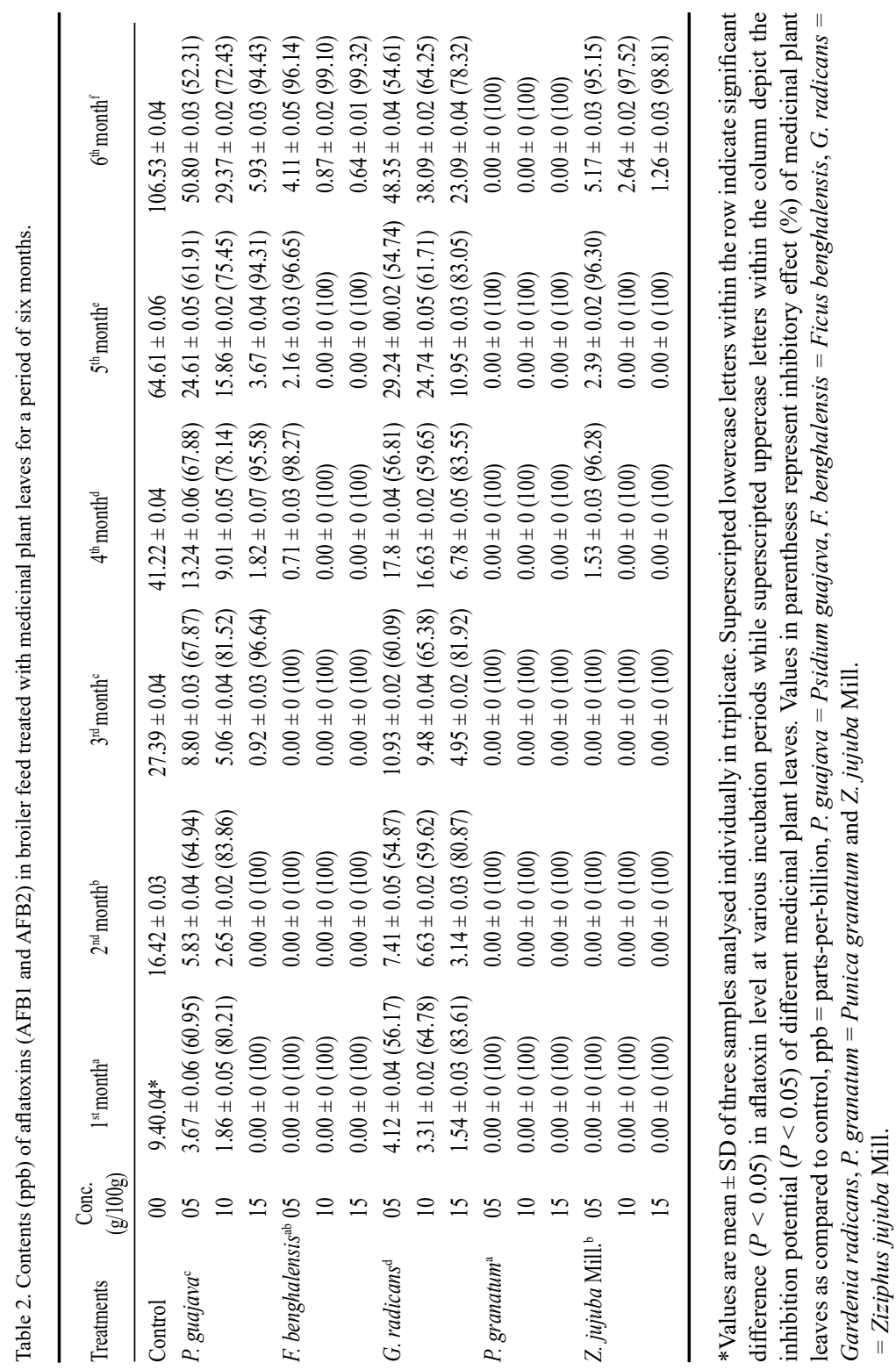

\section{Discussion}

Contaminated feed can be harmful to poultry as well as to the consumers because of the toxins contained in poultry products (Iqbal et al. 2015b). Ziziphus jujuba Mill. contains flavonoids, vitamin C, triterpenic acids, phenolics, and polysaccharides (Gao et al. 2013), whereas ellagic acid, ellagitannins (including punicalagins), punicic acid and other fatty acids, flavonoids, anthocyanidins, anthocyanins, estrogenic flavonols, and flavones are the 


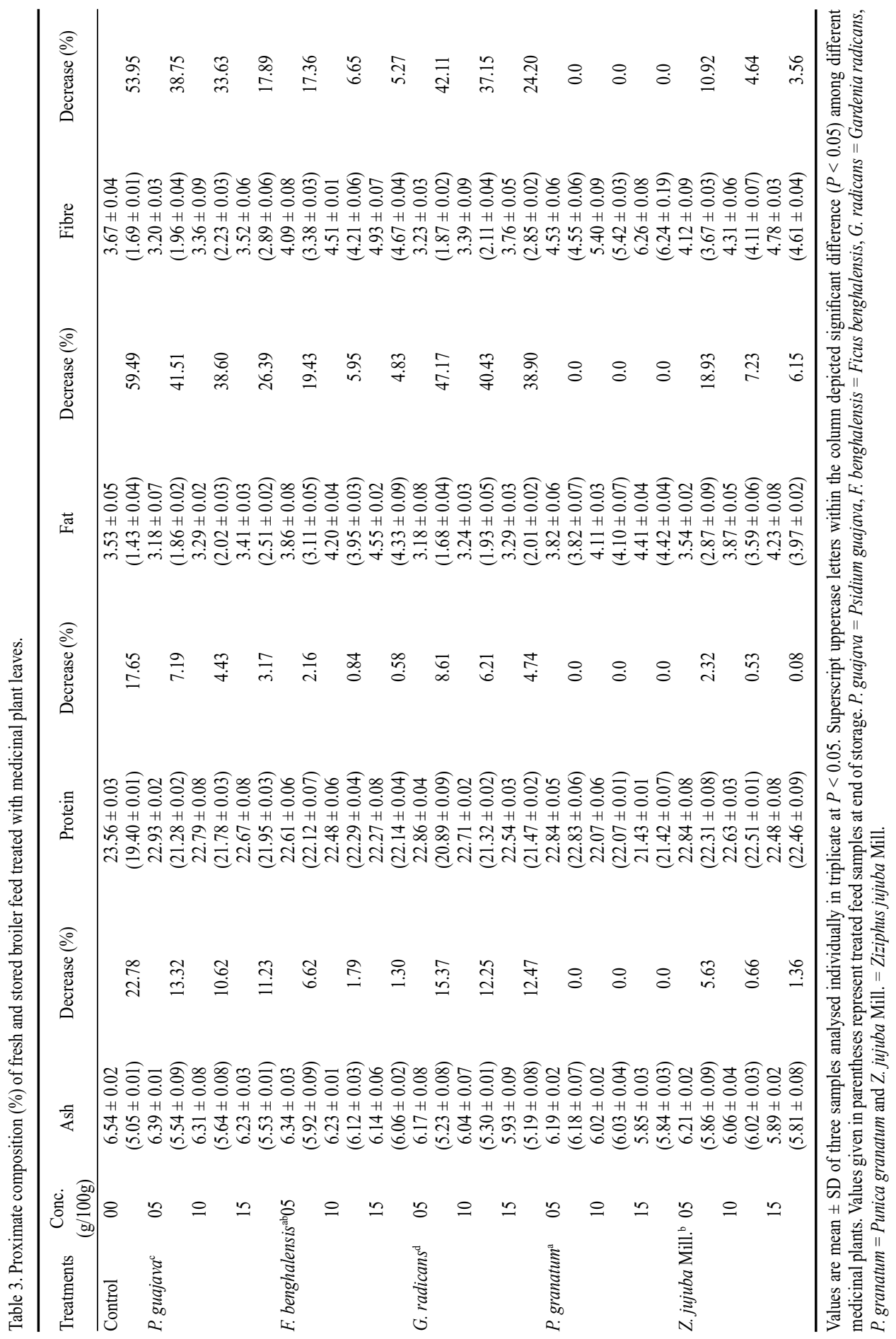




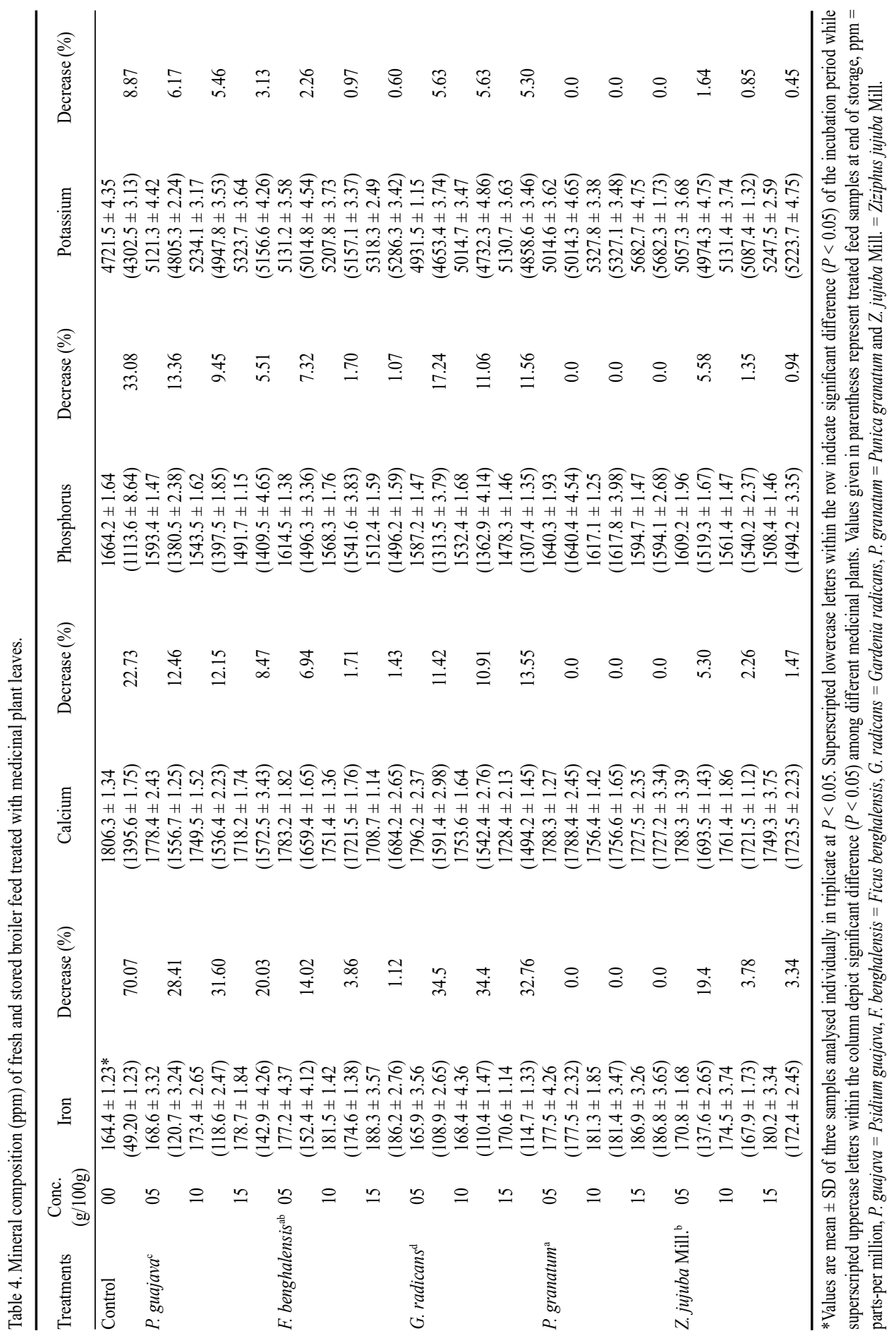


major constituents of $P$. granatum (Viladomiu et al. 2013). Ficus benghalensis contains flavonoids, coumarins, leucocyanidins, terpenes as major components (Sankaranarayanan and Sampathkumar 2012). Similarly, allic acid, catechin, chlorogenic acid, caffeic acid, epicatechin, rutin, quercitrin, isoquercitrin, quercetin, kaempferol, glycosylated campeferol, tocopherol, $\beta$-carotene and lycopene are the major constituents of P. guajava (Araújo et al. 2015). So far, the FATs inhibition in A. flavus inoculated feed sample treated with leaf powder might be due to the bioactivity of these bioactive compounds. The components present in plants have beneficial effects but toxic effects of certain plant components have also been reported, i.e., the oestrogenic effect of isoflavonoids or the toxicity of coumarins. Tannins in the feed of monogastric animals could reduce bioavailability and utilization of proteins (Roy et al. 1988; Bankole 1997; Abou-Arab et al. 1999; Soliman and Badeaa 2002; Romagnoli et al. 2007).

The antimicrobial assay revealed that the plants under investigation have significant antifungal activities, revealing the presence of bioactive compounds in the extracts. Psidium guajava and $G$. radicans were found to have promising antifungal activities. The medicinal plants that inhibit the growth of A. flavus at very low concentration are considered potent antifungal agents. The antifungal activities of plant extracts can be correlated with the secondary metabolites having antifungal agents (Sharma and Kumar 2008; Sankaranarayanan and Sampathkumar 2012; Gao et al. 2013; Viladomiu et al. 2013; Araújo et al. 2015).

Poultry feed treated with plant powder revealed that the medicinal plants have promising efficiency for the inhibition of AFT production by A. flavus. Previous reports also revealed that spices, plant extracts, essential oils have proven to exert efficient antifungal activities against toxigenic microorganisms (Shi et al. 2006; Inan et al. 2007). The medicinal plants investigated in our study inhibited $A$. flavus growth efficiently and as a result, the contents of aflatoxins were also reduced.

Results of the present investigation are in line with Dahham et al. (2010), who reported that the methanolic extracts of $P$. granatum have a potent antifungal activity and correlated it with phytochemicals in extracts including phenols, flavonoids and tannins.

Treated feed samples showed a slight change in the proximate composition and this slight decrease in proximate contents could be due to AFTs production because AFTs affect proximate contents and ultimately, lead to bad nutritive quality. Results revealed that medicinal plant leaf supplementation reduced the risk of AFTs, production by A. flavus without compromising the proximate components. The decrease in protein contents was due to fungus growth because during proliferation the protein is assimilated in the synthesis of protoplasm (Aboloma and Moriike 2012). Previous findings also support these results i.e., change in proximate composition in almond, inoculated with $A$. flavus reduced crude fat from $11.5 \%$ to $14.7 \%$ (Ali et al. 2009). The decrease in fat contents of the feed might be due to the lipolytic activity of the fungus. Results revealed that feed treated with plant leaves did not change the mineral contents over the entire storage period. The decrease in mineral contents was significantly higher in control compared to treated samples. The detrimental effects of AFTs on the stored feed observed in the present investigation are in line with previous studies. Authors have reported a significant decrease in $\mathrm{Fe}, \mathrm{Ca}, \mathrm{P}$ and $\mathrm{K}$ contents in $A$. flavus contaminated Dialium guineense and the $\mathrm{Fe}, \mathrm{Ca}, \mathrm{P}$ and $\mathrm{K}$ contents were also decreased in A. flavus inoculated almond, and these findings are in line with previous studies that fungus may affects the mineral contents (Ali et al. 2009; Aboloma and Moriike 2012). A decrease in $\mathrm{P}$ contents in papaya and mango fruits by fungal contamination has also been reported because $\mathrm{P}$ is assimilated by microorganisms as inorganic phosphate and is incorporated into phospholipids and nucleic acids as well as ATP synthesis (Pawar 2012). In another report, a direct relationship between $\mathrm{P}$ contents and microbial growth was observed (Fagbohun and Faleye 2012). In the present investigation, $P$. guajava, $F$. benghalensis, $G$. radicans, $P$. granatum and $Z$. jujuba also showed a promising anti-aflatoxigenic activities and the growth 
of A. flavus was inhibited efficiently; however, P. granatum at very low concentration activity was excellent for the inhibition of AFTs (AFB1 and AFB2) production by A. flavus over the period of six months of storage without compromising the proximate composition and mineral contents of the feed. So far, the plants under investigation could be potential candidates for the control of AFT production by A. flavus in stored poultry feed.

\section{Acknowledgements}

Higher Education Commission (HEC) of Pakistan is acknowledged for providing funds through Indigenous PhD Fellowship (PIN \# 074-0923-ps4-258).

\section{References}

Aboloma R, Moriike E 2012: Fungi associated with Irvingia gabonensis (Ogbono) and Colocynthis citrullus (Egusi) seeds sold in markets in Ado-Ekiti, Ekiti state Nigeria. J Nat Prod Plant Resour 2: 423-426

Abou-Arab A, Kawther MS, El Tantawy M, Badeaa RI, Khayria N 1999: Quantity estimation of some contaminants in commonly used medicinal plants in the Egyptian market. Food Chem 67: 357-363

Adaramola B, Onigbinde A, Shokunbi O 2016: Physiochemical properties and antioxidant potential of Persea americana seed oil. Chem Int 2: 168-175

Adaramola B, Onigbinde A 2017: Influence of extraction technique on the mineral content and antioxidant capacity of edible oil extracted from ginger rhizome. Chem Int 3: 1-7

Ahmad I, Anjum M, Hanif M 2012: Prevalence of poultry diseases at high altitudes of district Poonch Aazad Jammu \& Kashmir. Pak J Sci 64: 334-336

Ali E, Saleemullah FA, Khan BA, Zubair A 2009: Aflatoxin contamination and mineral profile of almond seeds. Mycopath 7: 39-44

Anjum M, Khan S, Sahota A, Sardar R 2012: Assessment of aflatoxin B1 in commercial poultry feed and feed ingredients. J Anim Plant Sci 22: 268-72

AOAC 1990: Official Methods of Analysis," Association of Official Analytical Chemists, Arlington, VA, USA, $84 \mathrm{p}$.

Araújo HM, Rodrigues FF, Costa WD, de FA Nonato C, Rodrigues FF, Boligon AA, Athayde ML, Costa JG 2015: Chemical profile and antioxidant capacity verification of Psidium guajava (Myrtaceae) fruits at different stages of maturation. EXCLI J 14, 1020

Asif M 2015a: Antiviral and antiparasitic activities of various substituted triazole derivatives: A mini. Chem Int 1: $71-80$

Asif M 2015b: Anti-neuropathic and anticonvulsant activities of various substituted triazoles analogues. Chem Int 1: 174-183

Asif M 2015c: Anti-tubercular activity of some six membered heterocycle compounds. Chem Int 1: 134-163

Asif M 2015d: Chemical characteristics and nutritional potentials of unsaturated fatty acids. Chem Int 1: 118-133

Asif M 2015e: Chemistry and antioxidant activity of plants containing some phenolic compounds. Chem Int 1: 35-52

Asif M 2015f: Pharmacologically potentials of different substituted coumarin derivatives. Chem Int 1: 1-11

Bankole S 1997: Effect of essential oils from two Nigerian medicinal plants (Azadirachta indica and Morinda lucida) on growth and aflatoxin B1 production in maize grain by a toxigenic Aspergillus flavus. Lett Appl Microbiol 24: 190-192

Chow K 1980: Storage problems of feedstuffs. Fish Feed Technology, Pillay TVR (Ed.). FAO, Rome, 215-225

Dahham SS, Ali MN, Tabassum H, Khan M 2010: Studies on antibacterial and antifungal activity of pomegranate (Punica granatum L.). Am Eurasian J Agric Environ Sci 9: 273-281

Fagbohun E, Faleye O 2012: The nutritional and mycoflora changes during storage of groundnut (Arachis hypogea). Int J Agron Agric Res 2: 15-22

Gao Q-H, Wu C-S, Wang M 2013: The jujube (Ziziphus jujuba Mill.) fruit: a review of current knowledge of fruit composition and health benefits. J Agric Food Chem 61: 3351-3363

Hamid AA, Oguntoye SO, Alli SO, Akomolafe GA, Aderinto A, Otitigbe A, Ogundare AM, Esinniobiwa QM, Aminu RO 2016: Chemical composition, antimicrobial and free radical scavenging activities of Grewia pubescens. Chem Int 2: 254-261

Inan F, Pala M, Doymaz I 2007: Use of ozone in detoxification of aflatoxin B1 in red pepper. J Stored Prod Res 43: 425-429

Iqbal M, Abbas M, Arshad M, Hussain T, Khan AU, Masood N, Tahir MA, Hussain SM, Bokhari TH, Khera RA 2015a: Gamma radiation treatment for reducing cytotoxicity and mutagenicity in industrial wastewater. Pol J Environ Stud 24: 2745-2750

Iqbal M, Bhatti IA 2015: Gamma radiation/ $/ \mathrm{H}_{2} \mathrm{O}_{2}$ treatment of a nonylphenol ethoxylates: degradation, cytotoxicity, and mutagenicity evaluation. J Hazard Mater 299: 351-360

Iqbal M, Nisar J 2015: Cytotoxicity and mutagenicity evaluation of gamma radiation and hydrogen peroxide treated textile effluents using bioassays. J Environ Chem Eng 3: 1912-1917 
Iqbal M 2016: Vicia faba bioassay for environmental toxicity monitoring: a review. Chemosphere 144: 785-802

Iqbal M, Nisar J, Adil M, Abbas M, Riaz M, Tahir MA, Younus M, Shahid M 2017: Mutagenicity and cytotoxicity evaluation of photo-catalytically treated petroleum refinery wastewater using an array of bioassays. Chemosphere 168: 590-598

Iqbal SZ, Jinap S, Pirouz A, Faizal AA 2015b: Aflatoxin M1 in milk and dairy products, occurrence and recent challenges: A review. Trend Food Sci Technol 46: 110-119

Khalil IA, Mannan F 1990: Colorimetry and Flame photometry. In: Chemistry One (Bio-analytical chemistry. $2^{\text {nd }}$ edn. Taj Printing Press, Peshawar, Pakistan, $131 \mathrm{p}$.

Mahesar S, Sherazi S, Niaz A, Bhanger M, Rauf A 2010: Simultaneous assessment of zinc, cadmium, lead and copper in poultry feeds by differential pulse anodic stripping voltammetry. Food Chem Toxicol 48: 2357-2360

Mahoney N, Molyneux RJ 2004: Phytochemical inhibition of aflatoxigenicity in Aspergillus flavus by constituents of walnut (Juglans regia). J Agric Food Chem 52: 1882-1889

MLD 2009: Ministry of Livestock and Development, Pakistan Economy Survey, 2008-2009, pp 32- 37

Mushtaq M, Sultana B, Anwar F, Khan MZ, Ashrafuzzaman M 2012: Occurrence of aflatoxins in selected processed foods from Pakistan. Int J Mol Sci 13: 8324-8337

Mushtaq M, Bhatti HN, Iqbal M, Noreen S 2016: Eriobotrya japonica seed biocomposite efficiency for copper adsorption: Isotherms, kinetics, thermodynamic and desorption studies. J Environ Manage 176: 21-33

Nadeem R, Manzoor Q, Iqbal M, Nisar J 2016: Biosorption of Pb (II) onto immobilized and native Mangifera indica waste biomass. J Ind Eng Chem 35: 185-194

Ngobiri N, Okorosaye-Orubite K 2017: Adsorption and corrosion inhibition characteristics of two medicinal molecules. Chem Int 3: 185-194

Pawar V 2012: Biochemical status of fruit under the influence of post-harvest fungi: a review. Curr Bot 3: 26-27

Peter UC, Chinedu U 2016: Model prediction for constant area, variable pressure drop in orifice plate characteristics in flow system. Chem Int 2: 80-88

Qureshi K, Ahmad M, Bhatti I, Iqbal M, Khan A 2015: Cytotoxicity reduction of wastewater treated by advanced oxidation process. Chem Int 1: 53-59

Romagnoli B, Menna V, Gruppioni N, Bergamini C 2007: Aflatoxins in spices, aromatic herbs, herb-teas and medicinal plants marketed in Italy. Food Control 18: 697-701

Roy A, Sinha K, Chourasia H 1988: Aflatoxin contamination of some common drug plants. Appl Environ Microbiol 54: 842-843

Sankaranarayanan S, Sampathkumar G 2012: Evaluating the antibacterial activity of flavonoids extracted from F. benghalensis. Int J Pharma Biol Res 3: 7-18

Saxena M, Saxena J, Nema R, Singh D, Gupta A 2013: Phytochemistry of Medicinal Plants. J Pharma Phytochem 1: $168-182$

Sayed M 2015: Efficient removal of phenol from aqueous solution by the pulsed high-voltage discharge process in the presence of $\mathrm{H}_{2} \mathrm{O}_{2}$. Chem Int 1: 81-86

Sharma B, Kumar P 2008: Extraction and pharmacological evaluation of some extracts of Tridax procumbens and Capparis decidua. Int J Appl Res Nat Prod 1: 5-12

Shi Y, Xu Z, Feng J, Wang C 2006: Efficacy of modified montmorillonite nanocomposite to reduce the toxicity of aflatoxin in broiler chicks. Animal Feed Sci Technol 129: 138-148

Shoukat S, Bhatti HN, Iqbal M, Noreen S 2017: Mango stone biocomposite preparation and application for crystal violet adsorption: A mechanistic study. Micropor Mesopor Mater 239: 180-189

Soliman K, Badeaa R 2002: Effect of oil extracted from some medicinal plants on different mycotoxigenic fungi. Food Chem Toxicol 40: 1669-1675

Stack J, Carlson M 2003: NF571 Aspergillus flavus and aflatoxins in corn, plant diseases, C-18, field crops. Lincoln: Historical Materials from University of Nebraska

Tahir MA, Bhatti HN, Iqbal M 2016a: Solar Red and Brittle Blue direct dyes adsorption onto Eucalyptus angophoroides bark: Equilibrium, kinetics and thermodynamic studies. J Environ Chem Eng 4: 2431-2439

Tahir N, Bhatti HN, Iqbal M, Noreen S 2016b: Biopolymers composites with peanut hull waste biomass and application for Crystal Violet adsorption. Int J Biol Macromol 94: 210-220

Ukpaka C 2016a: BTX Degradation: The concept of microbial integration. Chem Int 3: 8-18

Ukpaka C 2016b: Development of model for bioremediation of crude oil using moringa extract. Chem Int 2: 19-28

Ukpaka C 2016c: Empirical model approach for the evaluation of $\mathrm{pH}$ and conductivity on pollutant diffusion in soil environment. Chem Int 2: 267-278

Ukpaka C 2016d: Predictive model on the effect of restrictor on transfer function parameters on pneumatic control system. Chem Int 2: 128-135

Viladomiu M, Hontecillas R, Lu P, Bassaganya-Riera J 2013: Preventive and prophylactic mechanisms of action of pomegranate bioactive constituents. Evid-Based Compl Alt Med 2013: 1-18

Volcani Center I 2004: Control of mycotoxins in storage and techniques for their decontamination. Mycotoxins in food, Detection and Control; Magan N, Olsen M (Eds); CRC Press, Woodhead Publishin Limited: Abington Hall, Abington, MA, USA, pp 190-223

Wayne P 2002: National committee for clinical laboratory standards. Performance standards for antimicrobial disc susceptibility testing, 12 . 